\title{
A PRELIMINARY DESIGN STUDY FOR AN EXPANDER LIQUID OXYGEN TURBOPUMP
}

\section{Maeding, L. Souverein, D. Hummel, S. Koenigbauer, A. Wagner, and J. Alting}

Airbus DS GmbH

Munich 81633, Germany

In the recent years, Airbus DS GmbH started a turbopump initiative to buildup fundamental capabilities in analyzing and designing turbomachinery within a German national funded program "TARES." Turbomachinery is widely used in different rocket propulsion systems and include such parts as pumps and turbines. Turbines are used for generating power required by pumps in order to feed the propellants to the thrust chamber. The paper is dedicated to present an overview about currently ongoing conceptual design activities of turbomachinery covering the main design phases like TPA (TurboPump Assembly) layout tradeoff; rotational speed selection with respect to efficiency and cavitation; flow path design techniques including blade profiling; computer-aided design (CAD) work; and preliminary structural analyses. This paper presents the main outcome applying the established design logic to a liquid oxygen ( $\mathrm{LOx}$ ) turbomachinery. The component is designed based on a dedicated specification for an expander cycle type engine. This includes a LOx pump unit comprising inducer and impeller as well as a subsonic single stage reaction turbine. For the turbine drive, gaseous hydrogen $\left(\mathrm{GH}_{2}\right)$ heated within the thrust chamber cooling circuit is used. Within this paper, a general overview about the preliminary work results of pump and turbine sizing, profiling, performance estimation as well as structural aspects is given.

\section{NOMENCLATURE}

c Theoretical spouting velocity, $\mathrm{m} / \mathrm{s}$

$d$ Pump impeller outlet diameter, $\mathrm{m}$

$D_{s}$ Specific diameter

(C) The Authors, published by EDP Sciences. This is an open access article distributed under the terms of the Creative Commons Attribution License 4.0 (http://creativecommons.org/licenses/by/4.0/). 
$H \quad$ Pump head, $\mathrm{J} / \mathrm{kg}$

$H_{\text {loss }} \quad$ Pump inlet losses, $\mathrm{J} / \mathrm{kg}$

$n \quad$ Rotational speed, rpm

NPSH Net Positive Suction Head, J/kg

$N_{s} \quad$ Specific speed

$N_{\text {ss }} \quad$ Suction specific speed

$p_{\text {total }}$ Stagnation pump inlet pressure, $\mathrm{Pa}$

$p_{\text {vapor }}$ Fluid vapor pressure at inlet conditions, $\mathrm{Pa}$

$Q \quad$ Volume flow rate, $\mathrm{m}^{3}$

$u \quad$ Circumferential pitchline velocity, $\mathrm{m} / \mathrm{s}$

$u / c \quad$ Pitchline velocity vs. theoretical spouting velocity

$\Delta H \quad$ Pump head, $\mathrm{m}$

$\eta \quad$ Pump/turbine efficiency

$\rho \quad$ Turbine reaction degree

\section{Subscripts}

base $\quad$ Existing reference pump used for parameter scaling

lower value Minimum assessed rotational speed by similarity approach

LOxTPA 120-kilonewton TPA to be designed within this study

nominal Nominal value used for LOx TPA design

upper value Maximum assessed rotational speed by similarity approach

\section{INTRODUCTION}

In recent years, a turbopump initiative has been started at Airbus DS GmbH as a part of a German nationally funded research programme "TARES." The main objective of this initiative is to design an LOx TPA for a 120-kilonewton thrust class upper stage expander cycle rocket engine. To achieve this goal, an overall design and layout definition logic has been established covering design methods, software requirements, and anchoring using simulation tools and inhouse heritage. In parallel, available designs and test data have been used for method anchoring.

Based on a proposed 120-kilonewton upper stage $\mathrm{LOx}-\mathrm{LH}_{2}$ (liquid hydrogen) expander cycle pump specification and a corresponding trade-off, an LOxturbopump unit (TPU) has been designed. Hydrodynamic characteristics as well as the cavitation behavior have been evaluated by empirical and computational fluid dynamics (CFD) methods. The several design steps have been anchored using in-house and public data. Several empirical methods within the design process have been analyzed, discussed, and used in order to create an initial pump design for further design optimization. 
The matching subsonic turbine design is based on a preselected axial stage configuration with the ambition of simplicity at a sufficiently high overall efficiency. After defining the main flow path, different approaches for airfoil definition have been investigated, providing a basis design for further optimization using CFD as well. For performance prediction, beside empirical methods, CFD has been applied.

Based on the main data obtained by the first design loop, a three-dimensional (3D) model of the overall turbomachinery has been established, allowing estimating several structural aspects like Eigen frequencies, critical rotational speed, and shaft bending dependent on the used bearings and seals. In the next phase, the $3 \mathrm{D}$ model will be also used to investigate and estimate the occurring radial and axial loads during operation for further design optimization.

\section{COMPANY TURBOPUMP ASSEMBLY KNOW-HOW AND HERITAGE}

Within Airbus DS Ottobrunn, several activities have been undertaken in the past in the field of turbopump design and testing. Noteworthy in this respect is the P111 staged combustion cycle rocket engine [1] that was developed and tested in Ottobrunn in the period from 1956 to 1968. Its single shaft turbopump comprises single stage radial LOx and kerosene pumps and a single stage axial turbine driven by an oxygen-rich preburner (Fig. 1). Over 200 tests have been performed with this 50-kilonewton engine hardware.

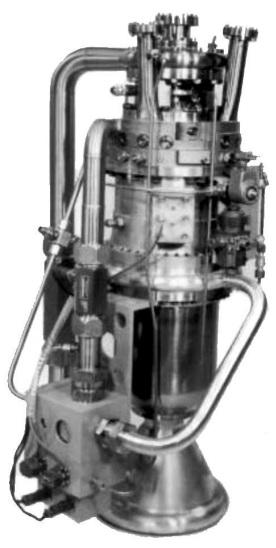

(a)

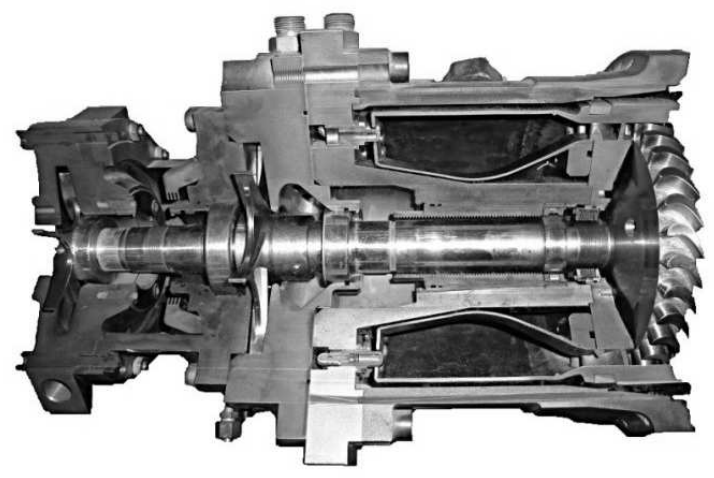

(b)

Figure 1 P111 engine $(a)$ and TPA with oxygen-rich preburner $(b)[1]$ 


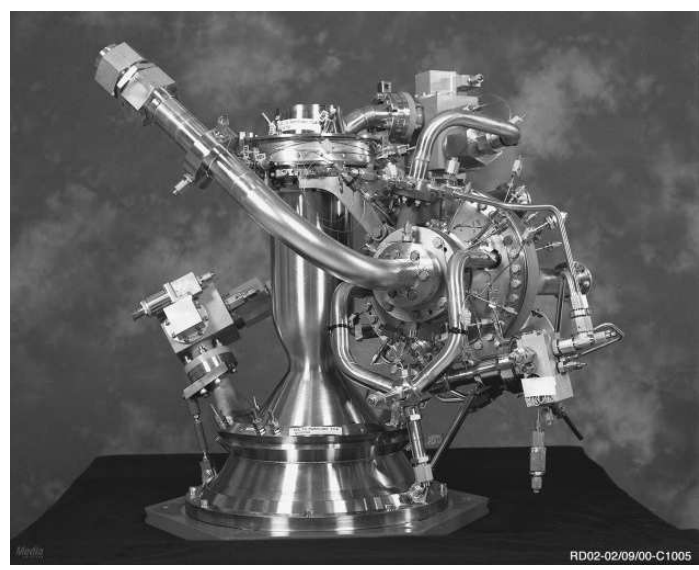

(a)

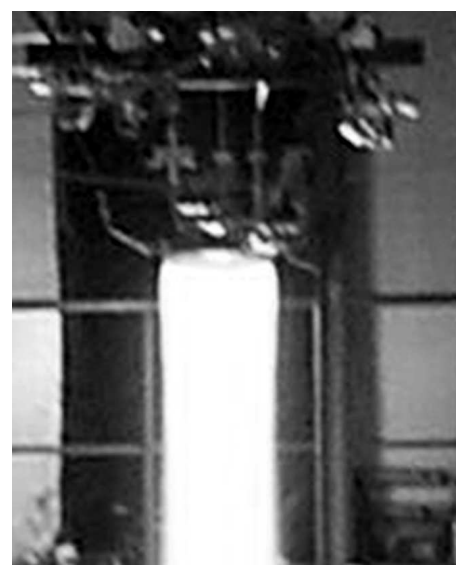

(b)

Figure 2 PW-Rocketdyne - Astrium ST turbopump demonstrator engine RS-72 (Pathfinder) [4]

During the early 1970s, a two-stage high-pressure $\mathrm{LH}_{2}$ pump [2] was developed and tested and at the same time, $\mathrm{LOx}$ " $\mathrm{H}_{2} \mathrm{O}$ " pump developments were initiated, both for application in a 200-kilonewton staged combustion engine. All development work was done in the frame of the Europa III program.

In the late 1990s, Airbus DS (Ottobrunn) - together with Rocketdyne developed and tested the RS-72 (Pathfinder), a storable turbopump-fed engine with a thrust range of $46-56 \mathrm{kN}$ (Fig. 2) [3]. In the frame of these development tests, additional run-in engine tests were performed in Lampoldshausen in Germany using a Russian turbopump [4]. Other heritage includes the LOx Vulcain 1 and Vulcain 2 turbopump tests that were performed under contract of AVIO till 2000 on the P59 test facility in Ottobrunn.

\section{DESIGN OF A 120-KILONEWTON LIQUID OXYGEN TURBOPUMP ASSEMBLY}

Within the national funded program "TARES," an LOx TPU conceptual design has been established for an $\mathrm{LOx} / \mathrm{LH}_{2}$ expander cycle having a vacuum thrust level of about $120 \mathrm{kN}$ (Fig. 3). Due to different physical properties of hydrogen and oxygen also with respect to the different cavitation behavior and for better overall performance optimization, two standalone TPUs have been chosen for combustion chamber propellant supply. The general flow schematic of this expander cycle is presented in Fig. 3. Thereby, the $\mathrm{LH}_{2}$ - and $\mathrm{LOx}$-turbopumps 


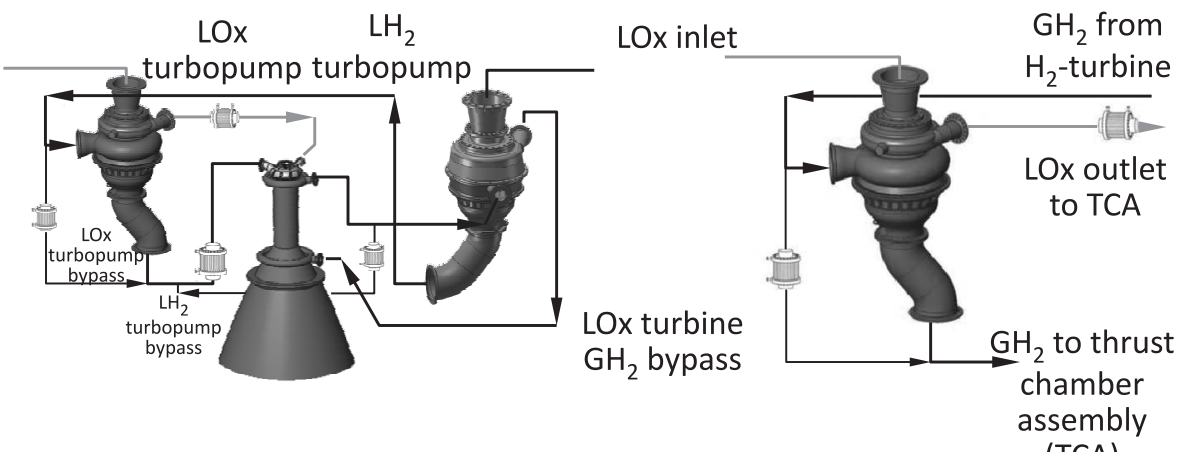

(TCA)

Figure 3 Expander cycle with two separate TPAs arranged in series

are arranged in series. Each turbopump is equipped with an additional bypass pipeline for performance adjustment and engine regulation. For this LOxturbopump design study, the following operational parameters at reference point have been used:

LOx pump:

- nominal flow rate (at the outlet) $22.8 \mathrm{~kg} / \mathrm{s}$;

- total pressure at the pump inlet 3.0 bar;

- pump inlet temperature $91.5 \mathrm{~K}$; and

- pump outlet total pressure 81.8 bar; and

$\mathrm{GH}_{2}$ turbine:

- mass flow rate (including LOx turbopump bypass) $2.67 \mathrm{~kg} / \mathrm{s}$;

- minimal required bypass mass flow rate $\geq 20 \%$;

- total pressure at the inlet 89.0 bar;

- inlet temperature $218 \mathrm{~K}$; and

- static pressure at the outlet 75.0 bar.

The dedicated turbopump design shall meet the following criteria within the operational envelope:

- maximum turbine and pump efficiency;

- sufficient cavitation margin;

- sufficient margin in terms of rotor critical speed;

- minimum TPA mass; and

- compact design with minimum momentum of inertia. 


\subsection{Liquid Oxygen Turbopump Assembly Conceptual Design}

To generate a target-oriented processing (workflow) of the several main issues, a general design logic as depicted in Fig. 4 has been established, taking into account two different pump configurations. These configurations, as depicted in Fig. 5, have been selected by a separately performed trade-off. All preselected pump layouts reflect the state-of-the-art design used in cryogenic and noncryogenic rocket engines. In the case of the pump with low head inducer (backup solution), a vanless diffuser has been chosen in order to get a layout with lower complexity. The selected baseline turbopump design consists of a high head inducer, radial impeller, and vaned diffuser. The vaned diffuser is used to reduce the radial impeller outlet velocity before entering the volute. This leads to an improvement in the overall pump efficiency.

Prior to starting this design work, a detailed literature survey covering [59], as well as in-house experience, has been performed. This survey has been also addressed to carry out the first validation and to anchor the chosen design software by redesigning of already existing units as well.

Based on the survey results, a quantification of the principle turbopump characteristics (main inlet geometry, number of blades, rotational speed, etc.) for the further conceptual design process was done by applying adequate similarities.

For the selection of rotational speed at reference conditions, the following criteria have been considered:

- sufficient cavitation margin (net positive suction head, NPSH) in the whole operational domain with respect to the reselected pump design (analytical justification);

- maximum pump and turbine efficiency level; and

- sufficient margin against critical rotational speeds.

In order to match these requirements, different scaling approaches were applied using similar already existing "base" pumps for scaling [5-10].

One approach is based on the specific speed $\left(N_{s}\right)$ equality of a "base" and the new "LOxTPA" pumps via the given volume flowrates ( $Q_{\text {base }}$ and $\left.Q_{\text {LOxTPA }}\right)$ and pressure head $\left(H_{\text {base }}\right.$ and $\left.H_{\text {LOxTPA }}\right)$ by adjusting the rotational speed of the "LOxTPA" $\left(n_{\text {LOxTPA }}\right)$ for a given rotational speed value $\left(n_{\text {base }}\right)$. Substituting the scaling factor by the given two dependencies, the unknown rotational speed has been determined, i. e., assuming the same specific speed for both pumps, the following mathematical function will be obtained:

$$
\begin{aligned}
N_{s} & =n \frac{\sqrt{\dot{Q}}}{H^{3 / 4}}=\text { const } \Rightarrow N_{s \text { base }}=N_{s \text { LOxTPA }} ; \\
n_{\text {LOxTPA }} & =n_{\text {base }} \sqrt{\frac{\dot{Q}_{\text {base }}}{\dot{Q}_{\text {LOxTPA }}}}\left(\frac{H_{\text {LOxTPA }}}{H_{\text {base }}}\right)^{3 / 4} .
\end{aligned}
$$






Figure 4 Pump design workflow 


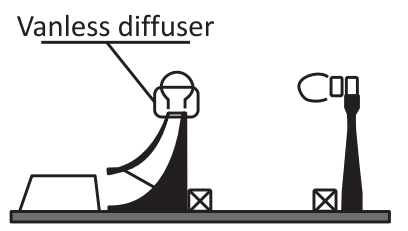

(a)

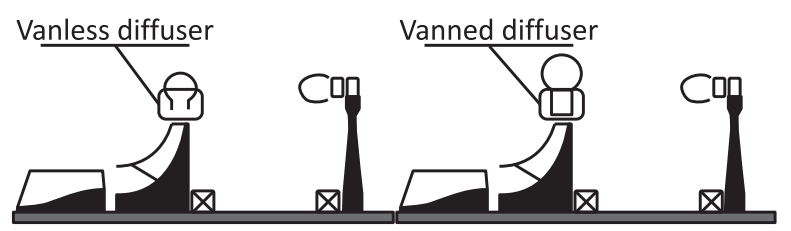

(b)

Figure 5 Preselected configurations for dimensioning: $(a)$ radial pump stage with low head inducer (backup); and (b) radial pump stage with high head inducer (baseline)

However, this approach does not take into account different inlet conditions in terms of pressure level with respect to the cavitation behavior. Therefore, the suction specific speed $\left(N_{\mathrm{ss}}\right)$ has been also used to assess the rotational speed $\left(n_{\text {LOxTPA }}\right)$, assuming the same value for the "base" and "LOxTPA" configurations:

$$
N_{\mathrm{ss}}=\frac{n \sqrt{\dot{Q}}}{\mathrm{NPSH}^{3 / 4}} \rightarrow \mathrm{NPSH}=\frac{p_{\text {total }}-p_{\text {vapor }}}{\rho}-H_{\text {loss }} \rightarrow H_{\text {loss }}
$$

where $H_{\text {loss }}$ is the additional inlet flow losses assumed to be equal for "base" and "LOxTPA" pumps;

$$
n_{\text {LOxTPA }}=n_{\text {base }} \sqrt{\frac{\dot{Q}_{\text {base }}}{\dot{Q}_{\text {LOxTPA }}}}\left[\frac{\mathrm{NPSH}_{\mathrm{LOxTPU}}}{\mathrm{NPSH}_{\text {base }}}\right]^{3 / 4} .
$$

Here, $n_{\text {base }}, \dot{Q}_{\text {base }}$, and $\mathrm{NPSH}_{\text {base }}$ are the values of the "base" pump configuration used for scaling.

Another approach presents the direct use of the $N_{s}-D_{s}$ design-point performance diagram as presented in Fig. 6. Comparing the results of the different approaches, covering a range from $n_{\text {lower value }}=22000 \mathrm{rpm}$ up to $n_{\text {upper value }}$ $=27000 \mathrm{rpm}$, an average rotational speed value of $n_{\text {nominal }}=25000 \mathrm{rpm}$ has been chosen for further pump design work. This value has been also chosen with respect to the turbine performance. A higher rotational speed tends to provide a higher turbine efficiency level. Taking into account the restricted operational envelope, a rotational speed of $25000 \mathrm{rpm}$ provides acceptable pump 


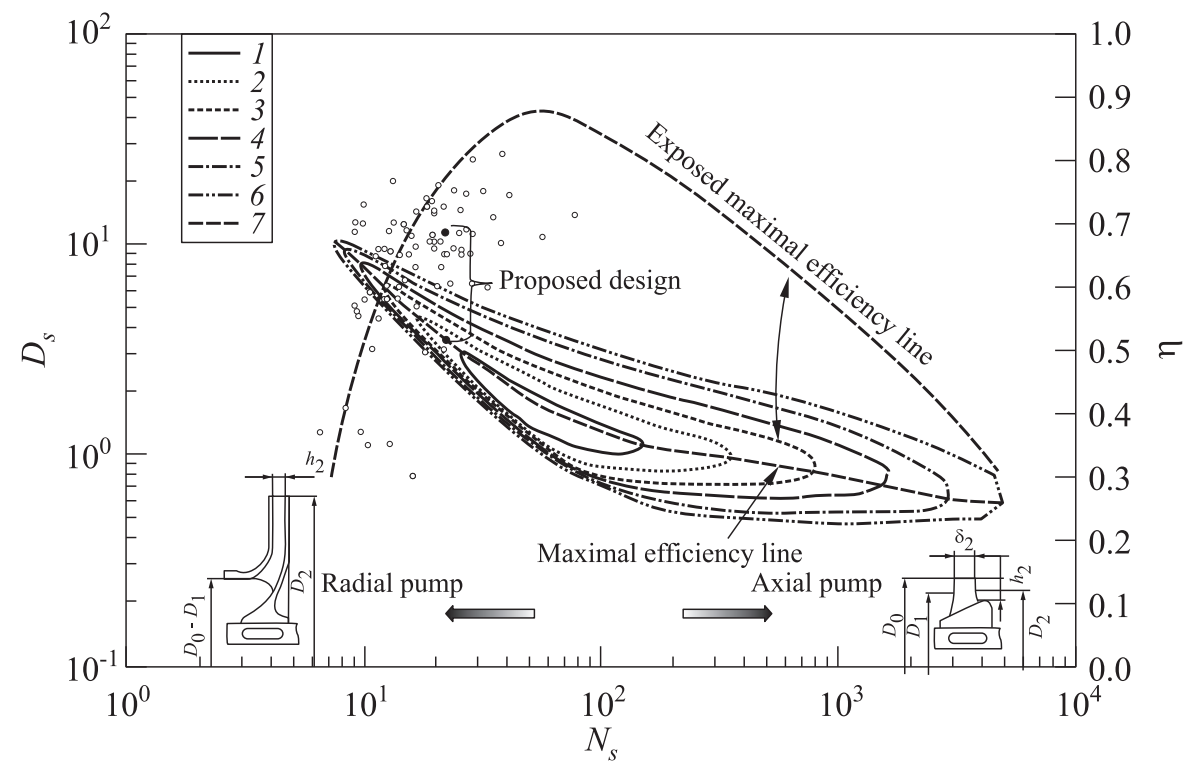

Figure 6 The $N_{s}-D_{s}$ design point performance diagram $\left(N_{s}=n\right.$ [rpm] $\left.\times \sqrt{q\left[\mathrm{~m}^{3} / \mathrm{s}\right]} /(\Delta H[\mathrm{~m}])^{3 / 4} ; D_{s}=d[\mathrm{~m}](\Delta H[\mathrm{~m}])^{0.25} / \sqrt{q\left[\mathrm{~m}^{3} / \mathrm{s}\right]}\right): 1-\eta=0.8 ; 2-$ $0.7 ; 3-0.6 ; 4-0.5 ; 5-0.4 ; 6-\eta=0.3$; and $7-$ maximal efficiency line

inlet conditions with respect to cavitation independently on the used inducer configuration.

\subsection{Pump Design}

The pump design has been made to satisfy the nominal operating conditions. Typically, the specific speed $N_{s}$ and the specific diameter $D_{s}$ are used for the pump type selection. Figure 6 shows the design-point performance diagram for various pumps in terms of $N_{s}$ and $D_{s}$. Based on this commonly used diagram, existing rocket pumps have been analyzed and the first efficiency and sizing assessment was done.

The design parameters have been compared to available/deduced values from existing LOx-turbopump hardware. With respect to the trade-off, different layouts have been selected for the first design phase mainly marked by the different inducer designs.

Predesigns have been made for the whole pump section to obtain a rough idea of the expected size and performance of the machine. A more detailed discussion on dedicated baseline pump design is given in [11]. 

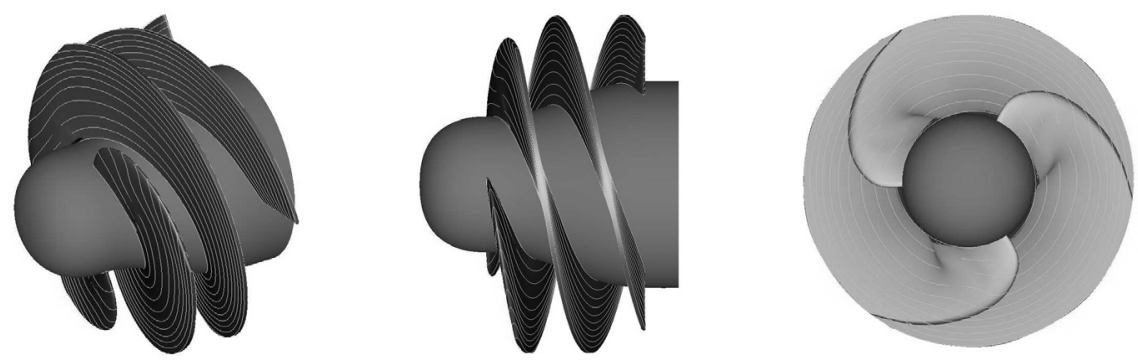

Figure 7 Final layout of the high head inducer of the baseline pump configuration

The impeller stage suction characteristics prescribe the need for an inducer to provide sufficient inlet pressure to the radial stage. Based on this necessary inducer head, a preliminary design has been generated. In addition, a parametric study has been made with the main focus on the effect of the cant angle and leading edge sweep on the inducer performance, as well as the effect of the tip clearance (all of which were kept to zero so far in the baseline design). The effect of these parameters on the flow field and the performance was evaluated by means of CFD focusing on the selected baseline configuration (Fig. 7).

Based on the inducer total outlet pressure and the required overall nominal pressure head requirement for the turbopump, the impeller head has been determined. In addition, a casing efficiency value had to be assumed as the first estimate to account for losses in stator stages, diffusers, and volute. The impeller has been designed to match the inducer configuration. The blade design has been made in free-form 3D modes.

In the case of the baseline configuration, two diffuser configurations have been generated based on the same meridian geometry: a vaneless variant and a vaned diffusor variant. The aim was to characterize the effect of vanes on the pump efficiency under otherwise identical conditions.

The draft layouts and the flow path parameter changes of the two different configurations are given in Fig. 8. At first instance, all further optimization efforts are only applied to the baseline configuration equipped with a high head inducer due to company heritage.

\subsection{Turbine Design}

A fundamental requirement in the design of a turbine is the efficient utilization of high-energy working fluid in the smallest obtainable configuration. The final turbine type and layout selection is influenced by several trade-off factors like: complexity, efficiency, weight, life, etc. Normally, all these factors are evaluated in conjunction with the overall turbopump design as well as the complete en- 
Pump $y$-axis view Pump 3D CAD view Clipped center plane


(a)
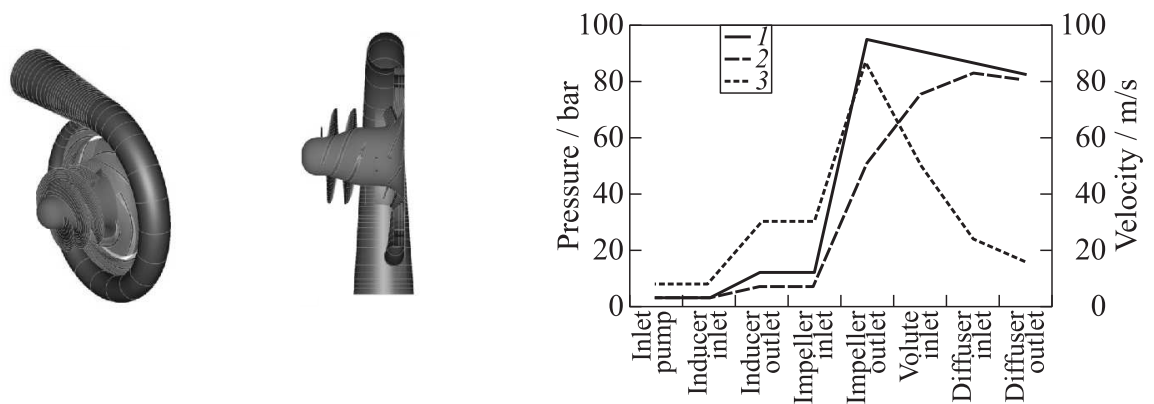

(b)

Figure 8 Draft pump design and flow path parameter evolution: 1 - total pressure; 2 - static pressure; and 3 - velocity. Backup configurations with low $(a)$ and high $(b)$ head inducers

gine. In this context, only the efficiency and the complexity have been used as the mostly driving parameters within the trade-off. Prior to starting with the design of the $\mathrm{GH}_{2}$ turbine, available data, for instance, of the P111 rocket engine turbine, have used to verify and anchor the design method including CFD calculations (Fig. 9). The figure also shows the numerical mesh used for the 3D CFD simulations of the redesigned turbine. The computational grid has a total size of $\sim 1.4$ million cells. It is divided into two domains: the stator domain with 500000 cells and the rotor domain with 900000 cells, both resolving a single blade. The results of this redesign work are presented in more detail in [11].

The P111 stage combustion single-stage axial turbine presents a full flow reaction turbine driven by an oxygen-rich gas having a temperature of about $1000 \mathrm{~K}$. The available documentation including test and design data as well as the still existing hardware has been used as input for a redesign and to generate a 3D model for CFD computation. 


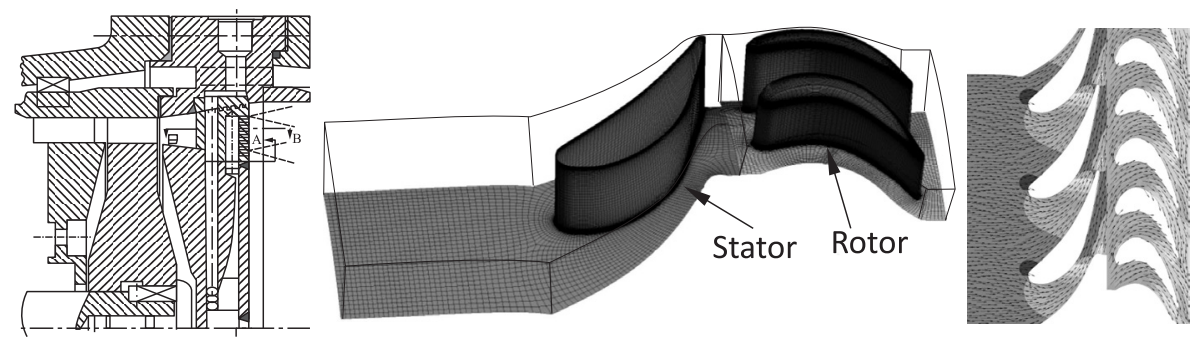

Figure 9 The P111 CFD turbine analysis

For preliminary turbine investigations and trade-off among several turbine candidates, the efficiency vs. the isentropic velocity ratio can be used. The isentropic velocity ratio $u / c$ (pitchline velocity vs. theoretical spouting velocity) determines the range of efficiency in which the new turbine operates. This velocity ratio can be used to illustrate and investigate the peak efficiency behavior of single- and multistage configurations as well as reacting staging. That means these curves serve to compare different turbine layouts based on certain initial estimates.

With respect to the dedicated application, the pressure ratio as well as the available energy have been kept constant for staging investigation. In order to

Table 1 Turbine main operating point data

\begin{tabular}{lc}
\hline Parameter & Value \\
\hline Power required & $236 \mathrm{~kW}$ \\
Inlet pressure & $89.0 \mathrm{bar}$ \\
Inlet temperature & $218 \mathrm{~K}$ \\
Mass flow & $2.67 \mathrm{~kg} / \mathrm{s}$ \\
Bypass & $\geq 20 \%$ \\
Mass flow (efficient) & $2.14 \mathrm{~kg} / \mathrm{s}$ \\
Outlet pressure & $75.0 \mathrm{bar}$ \\
\hline
\end{tabular}

perform such an investigation, three different staging types have been chosen keeping the loss coefficient constant within the stator and rotor grids. For these configurations, different reaction degrees as well as different first-stage stator outlet angles have been considered. Taking into account the low velocity ratio $u / c$, the maximum reaction degree $\rho$ for staging analysis has been fixed to 0.3 . Impulse staging is usually used for turbines with a velocity ratio below 0.35. These turbines are usually characterized by a high pressure ratio

linked to a sonic or supersonic flow. Reaction staging is marked by a significant lower pressure ratio operating at a velocity ratio above $0.4-0.45$.

The efficiencies used for further analysis are quoted on a total to static pressure basis. The initial parameters used for turbine staging investigation are listed in Table 1. Taking into account the low inlet temperature and the moderate available pressure change through the turbine, a frozen isentropic gas composition has been chosen to determine the velocity ratio. In order to determine the circumferential speed, an average turbine diameter of comparable size as the 




Figure 10 Turbine efficiency assessment for different staging

main dimension of the pump unit has been selected. The result of the efficiency estimation within a velocity ratio range up to 0.9 is depicted in Fig. 10.

The number of stages in a new turbine depends on the available working fluid energy, efficiency, and weight. Since the pressure ratio, inlet temperature, and mass flow at reference point are fixed, the efficiency level is affected by varying the diameter, flow angle, and the number of stages. However, the stage number has a huge impact on the reachable maximum efficiency level and its location with respect to the velocity ratio.

Analyzing one-, two- and three-stage turbine configurations and focusing, mainly, on the complexity of the three different designs, a single-stage configuration, having a reaction degree not greater than 0.15 , has been chosen as a baseline for further design work (see Figs. 10 and 11), due to the simplicity of its design. A single-stage turbine system has a significantly reduced number of elements to be designed and manufactured, increasing hereby the reliability of the overall system. However, this approach leads to some reservations regarding the achievable efficiency. In other words, such a design presents a compromise between efficiency and design complexity.

The impact of the stator outlet angle as well as stage reaction degree in the case of a single-stage configuration at nominal operational velocity ratio $u / c$ 


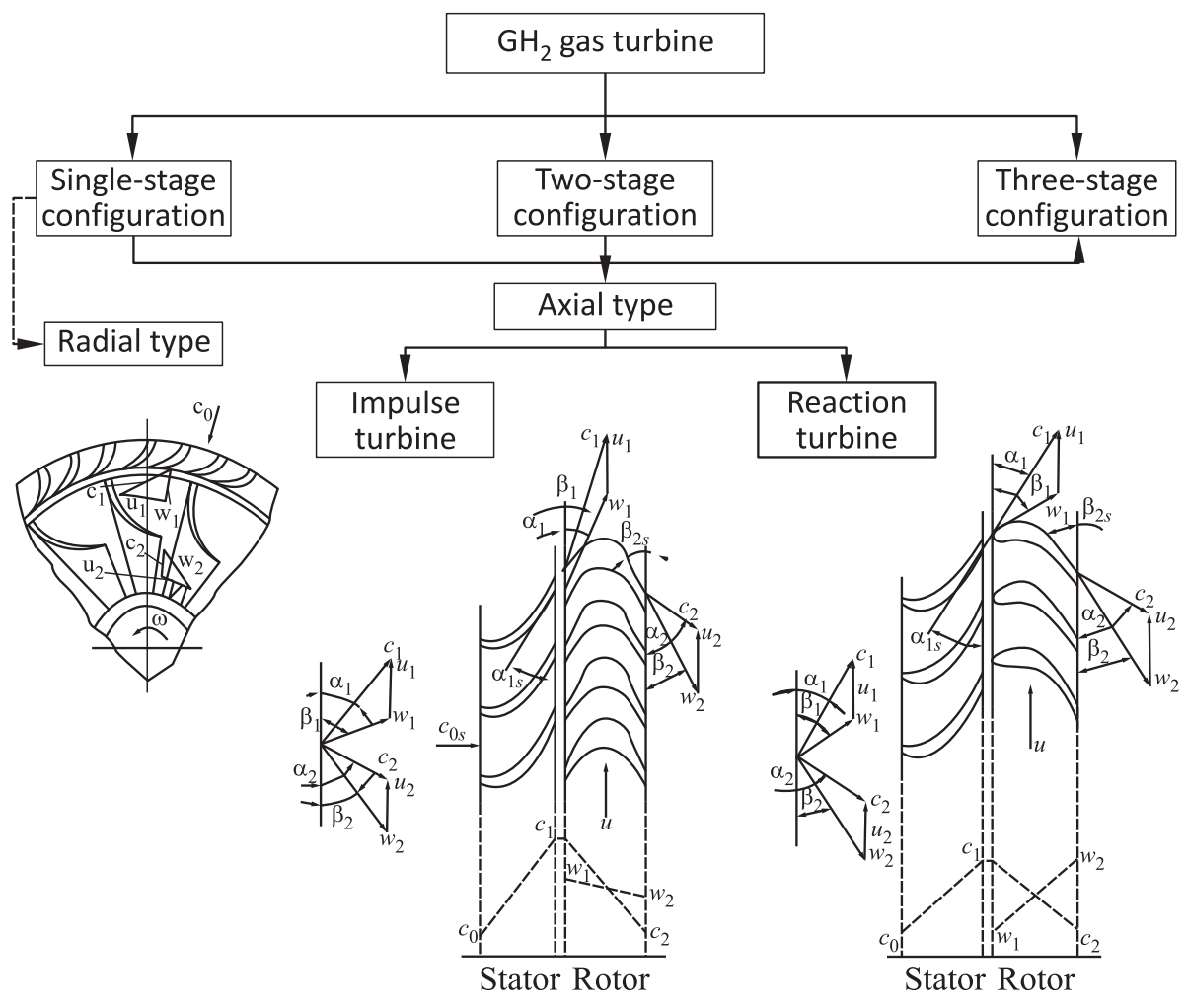

Figure 11 Turbine type trade-off: $c_{0}$-absolute stage inlet velocity; $c_{1}$ - absolute inlet velocity; $c_{2}$ - absolute outlet velocity; $w_{1}$ - relative inlet velocity; $w_{2}$ - relative outlet velocity; $u_{1}$ - inlet pitchline velocity; $u_{2}$ — inlet pitchline velocity; $\alpha_{1}$ and $\alpha_{2}-$ inlet/outlet blade angle; and $\beta_{1}$ and $\beta_{2}$ — inlet/outlet flow angle

results in an efficiency scattering. The possible efficiency scattering is marked by a light grey bar in Fig. 10 .

In order to establish a corresponding turbine design, the same approach as already described for the pump unit has been used. Taking into account the fixed initial values and a preselected middle turbine inlet diameter (also with respect to the maximum pump diameter), the gas path expansion was adjusted using in the first loop perspective loss coefficients. The middle turbine diameter has been also selected with respect to blade height, avoiding too small values inducing additional losses, especially in the rotating section. Performing iterative gas path calculations, an initial draft turbine design is developed by changing the corresponding design parameters. To minimize the exit losses, a minimized exit velocity with a vector close to an axial direction is required. Based on this 

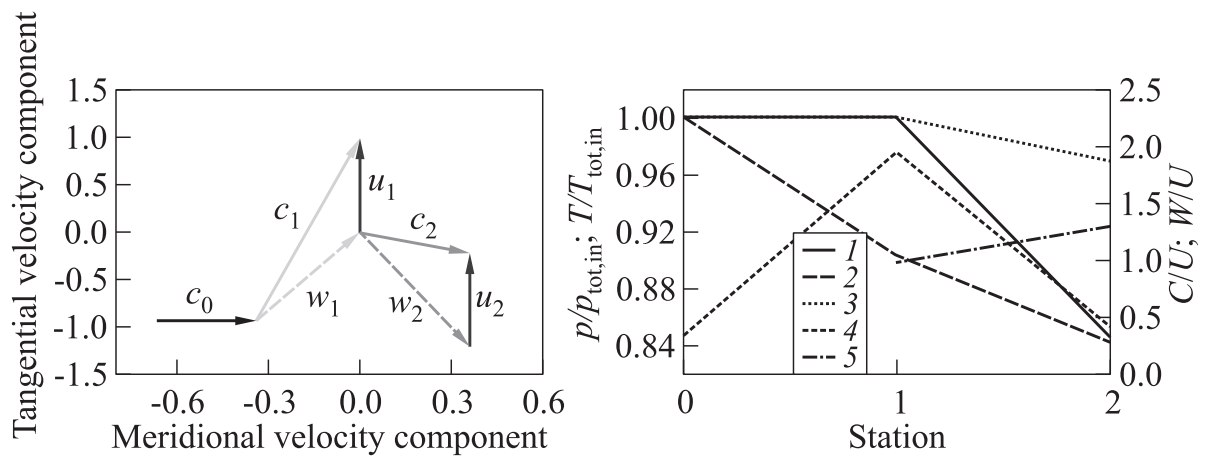

Figure 12 Turbine stage - parameter evolution: 1 - total pressure; 2 - static pressure; 3 - total temperature; 4 - total absolute velocity; and 5 - total relative velocity

initial design, the distribution of the main parameters has been checked prior to initiate the blade design for further CFD performance calculation and stage optimization. A diagram representative of the design point main parameters is given in Fig. 12 . The stage is marked by a low reaction degree and a nonaxial exit flow affecting the efficiency level of the stage.

In the next step, initial blade geometries for the stator and the rotor

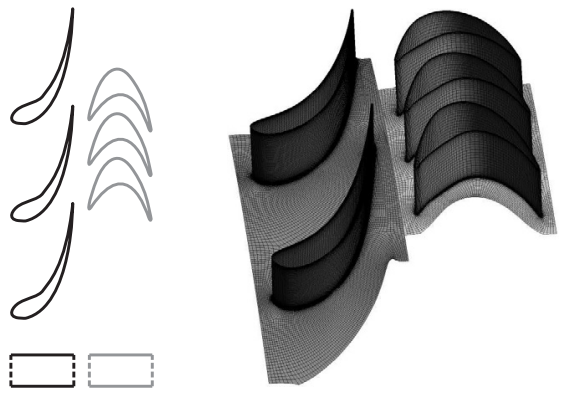

Figure 13 Turbine stage - airfoils have been generated (Fig. 13). The geometry shall develop the required gas path vector relationships and shall pass the $\mathrm{GH}_{2}$ mass flow at reference operation conditions.

The turbine airfoil (blading) design treats the flow path evolution under the given boundary conditions at inlet and outlet. For the blade profiling, the following main parameters have been used:

- in- and outlet angles;

- turning angles;

- axial width;

- stagger (chord) angle; and

- throat opening. 
Depending on the applied profiling method, the missing parameters will be determined using experience and/or available statistic data. Some of these parameters are mainly driven by the flow conditions in terms of velocity. Since within the turbine stage only a moderate pressure ratio will be realized, the blade design has been based on a typical subsonic flow grid. The highest velocity is reached at the stator exit.

The airfoil is always designed to meet a specific set of operational conditions taking also into account manufacturing specialties. In general, different approaches can be applied to generate a dedicated blade profile. All these approaches can be divided in three different groups:

(1) graphical design;

(2) analytical design; and

(3) design using standard airfoils.

The application of standard airfoils (widely used approach) is based on the direct implementation of a dedicated airfoil in the dedicated stage design adjusting only the main proportions by scaling with respect to the requirements. Such standardized airfoils were generated for certain flow conditions taking also into account the stage reaction degree and, especially, the velocity level. Airfoils of this group can be also generated using standard "flat" profiles having a certain thickness distribution. In this case, the airfoil will be matched to the predefined centerline. For the dedicated turbine stage design, two different methods have been applied. In the first loop, aerodynamic turbine airfoils have been used, substituted in the second loop by an analytical design approach (Bezier based curves) which gives a higher freedom especially with respect to the forming process of the flow channel between two blades. This method seems to be more convenient and allows also a fast blade shape adaptation especially with respect to the CFD design optimization loop.

Using these data, a complete turbine stage prototype has been established used for further CFD analysis and flow path optimization. More detailed information on the dedicated turbine design and its optimization are given in [4].

\subsection{Structural Analysis}

Structural analyses are addressed to determine the effects of all occurring loads on the structure and the corresponding components. That means these analyses are addressed to compute internal forces and stresses to verify the structural fitness. Within the first analyses, static and dynamic computations using ANSYS software have been done. Taking into account the experience in analyzing static loads occurring in thrust chambers and other space components, special emphasis was put on rotor dynamic. 
Rotor dynamic presents one of the most important points in the investigation of the turbopumps. In the frame of this work, it has been demonstrated that for all necessary dynamic simulations, appropriate software tools are available.

In general, the following inputs are always needed for structural investigations:

- geometry data (dimensions, wall thickness, etc.);

- material data (properties of all used materials);

- characteristics of bearings (stiffness and damping);

- characteristics of sealing (stiffness and damping);

- eccentricity of rotor (distribution and absolute values);

- nominal rotor speed with centrifugal forces;

- torsional moment (drive torque);

- pressures (distribution and absolute values);

- fluid velocities (distribution and absolute values); and

- temperatures (distribution, absolute values, and gradients).

For the designed rotor, as shown in Fig. 14a, a finite beam element model has been created. Once all dimensional requirements for a structure have been defined, it becomes necessary to determine the loads the structure must support. In order to design an adequate structure, it is, therefore, necessary at first to specify the loads that act on it. This requires a detail treatment of all radial and axial loads occurring on pump and turbine side.

To perform an accurate analysis, all information such as structural loads, geometry, support conditions, flow/leakage conditions, and materials properties must be known. The results of such an analysis typically include support reactions, stresses, and displacements. This information is then compared to criteria that indicate the conditions of failure. Advanced structural analysis may examine dynamic response, stability, and nonlinear behavior.

In the second continuing phase, a detailed model of the whole turbopump will be generated in order to calculate all occurring axial and radial loads for adjusting the seals and to determine the bearing specifications. Until then, a simplified rotor model consisting of the turbine, pump preselected seal package, and bearing with certain stiffness for rotor dynamic analysis was used mainly to determine the margin with respect to critical speeds. The applied materials, influencing the inertia and stiffness of the rotor, have been selected based on the results of the survey. Usually, in order to show the response spectrum as a function of the oscillation, the Campbell diagram (see Fig. 14b) is used. This diagram is used to evaluate the critical speed at different operating speeds. 


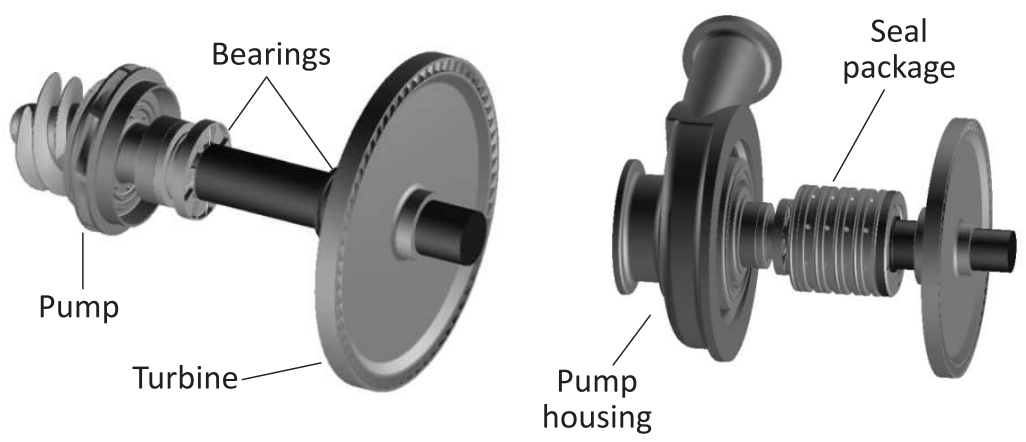

(a)

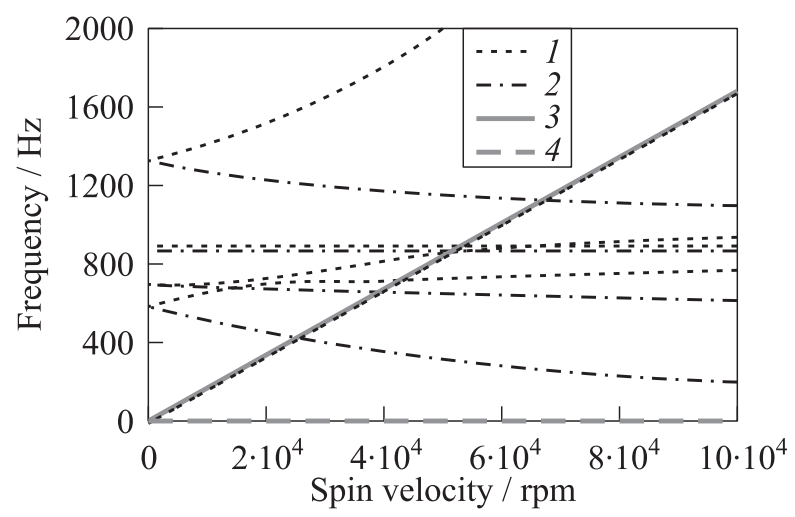

(b)

Figure 14 Rotor assembly for dynamic analysis: 1 - forward; $2-$ backward; $3-$ one-times spin speed; and 4 - stable

\section{FURTHER TURBOPUMP ASSEMBLY FUNDAMENTAL INVESTIGATION AND TEST ACTIVITIES}

As already mentioned above, in the early 1970s, an LOx turbopump " $\mathrm{H}_{2} \mathrm{O}$ " [2] was developed and manufactured at Airbus DS in Ottobrunn. Especially, the inducer unit was used for verifying and anchoring dedicated design tools including methods for performance and cavitation predictions. Since only restricted data are available, additional water tests will be performed at the University of Kaiserslautern, specializing in pump design, manufacturing, and testing. These tests will be conducted under adequate operational conditions using water as pump fluid. The results of these tests serve to anchor especially the CFD performance 
analyses and to improve the Airbus DS capabilities in cavitation prediction and inducer design optimization.

\section{CONCLUDING REMARKS}

The main goal of the presented program is to rebuild a certain turbopump competence covering not only the analysis of existing systems, but also to acquire skills in designing such systems. With respect to the initial proposal, a preliminary LOx turbopump design including the main components has been established preserving proven design heritage. In the frame of this project, a dedicated work flow has been established and applied including the application of design and analyses software. First, 3D CFD results have been obtained and analyzed for pump and turbine performance mapping and characterization. The steady-state pressure data have been applied for first ANSYS structural models. Further design work has to cover the investigations, especially of unsteady-state processes as well as further concerns related to airfoil, flow path, and axial thrust.

\section{ACKNOWLEDGMENTS}

This work has been performed within the National technology program TARES. This program is sponsored by the German Space Agency, DLR Bonn, under contract No. 50RL1210.

\section{REFERENCES}

1. Hopmann, H. 1999. Schubkraft für die Raumfahrt. Entwicklung der Raketenantriebe in Deutschland. Lemwerder, Stedinger. 480 p.

2. Rothmund, C.H., H. Hopmann, and E. Kirner. 1992. The early days of the $\mathrm{LOx} / \mathrm{LH}_{2}$ engines at SEP and MBB. 43rd Congress of the International Astronautical Federation. Washington, D.C. IAA 92-0195.

3. Butler, K., G. Langel, and G. Schmidt. 1999. Storable upper stage engine for global applications - Aestus II. 3rd Joint Propulsion Conference and Exhibit. DaimlerChrysler Aerospace. Technik der Flüssigkeits-Raketentriebwerke.

4. Obermaier, G., A. Goetz, G. Hagemann, P. Philipp, O. de Bonn, and C. Maeding. 2010. Storable propellant technology enhancements for low thrust engines roadmap and achievements. ASTRIUM Space Transportation. ESA 3AF Space Propulsion. San Sebastian, Spain. ESA 3AF 1840626.

5. Furst, J. K. 1973. Liquid rocket engine centrifugal flow turbopumps. NASA SP8109. 
6. Goirand, B., J.-F. Gallardo, and R. Bosson. 2000. Vinci hydrogen turbopump a new step in safe, faster and cheaper developments. AIAA Paper No. 2000-3156.

7. Guinzburg, A., M. Williams, and T. Ferguson. 2002. Deep throttle turbopump technology design concepts. JANNAF. Destin, FL.

8. Demiyanenko, Y., A. Dmitrenko, A. Ivanov, A. Kravchenko, V. Pershin, R. Bullock, J. Santiago, and M. Russ. 2004. Engineering and testing of a main oxidizer turbopump assembly for the RL60 engine. AIAA Paper No. 2004-3686.

9. Trollheden, S., B. Bergenlid, U. Palmnas, and S. Brodin. 2004. Turbopump turbines developed by VOLVO. AIAA Paper No. 2004-3687.

10. Rachuk, V., and N. Titkov. 2006. The first Russian $\mathrm{LOx}-\mathrm{LH}_{2}$ expander cycle LRE: RD0146. AIAA Paper No. 2006-4904.

11. Souverein, L., C. Maeding, T. Aichner, and M. Frey. 2015. Design and tool anchoring for a 120-kilonewton expander cycle rocket engine liquid oxygen turbopump. Progress in propulsion physics. Eds. M. Calabro, L. DeLuca, S. Frolov, L. Galfetti, and O. Haidn. EUCASS advances in aerospace sciences book ser. TORUS PRESSEDP Sciences. 11:591-610. 